\title{
Cultural and Local Concepts of Mental Illness among Rwandans Living in Finland and Belgium
}

\author{
Jean d'Amour Banyanga \\ Faculty of Education and Welfare Studies, Social Science, Developmental Psychology, Åbo Akademi University, \\ Vasa, Finland \\ Email: jean.banyanga@abo.fi
}

\begin{abstract}
The knowledge and understanding of cultural concepts of mental illness is essential to plan public mental health programs and aid projects in East and Central African countries. This study aims to understand the cultural concepts of mental illness and draw a useful framework that could inform the clinical practices of psychiatrists working with Rwandan people who were traumatized by their experiences during the 1994 genocide and its aftermath, living in Finland and Belgium. Questionnaires were dispatched in 27 different locations of Finland and Belgium in schools and churches (13 locations in Belgium \& 14 locations in Finland). A total of 341 respondents (166 males, 175 females), 50 from Finland and 291 from Belgium, participated in the study. The findings show that Rwandans in Belgium were more satisfied than those living in Finland, with friends, religious leaders, and spiritual healers helping them to cope with their trauma. Rwandans in Finland, on the other hand, relied on traditional means (wedding and dance), medicines and the use of alcohol as a coping mechanism more than those living in Belgium.
\end{abstract}

Keywords: Culture, local concepts, mental disorder, mental illness, Rwandans.

\section{Introduction}

People do not exist in isolation; they are born and grow up in specific social and cultural backgrounds. Those backgrounds are the context in which they place themselves in their social environment and play a major role in terms of personal meaning and value. People's cultural systems influence them as one way of being in the world (Delgado, 2009; Haarmann, 1986). Therefore, local concepts may have an impact on the life cycle of the society and it may affect the family structure, relations with others, role performance and responsibilities, marriage, work, communication patterns, living, and consumption, as well as health and illness behavior (Pronin, 2008; Hitlin, 2011). The term mental illness or "mental health disorder" is a mental malfunction which is a consequence of physical and chemical changes in the brain, but sometimes in other parts of the nervous system (Tyrer \& Steinberg, 2005). Some mental illnesses are the result of brain damage due to accidents, infections, old age and traumatic experiences.

According to a study by Rob \& Rosalyn (2014), it was suggested that mental illnesses may be due to organic damage, or they may be the result of severe and non-stop stress, depression, and anxiety, or a mixture of both mentioned. They mentioned that several issues contribute to the causes of mental illness, ranging from the physiological to the environmental. Aside from those cases in which brain tissue is damaged, mental and emotional disorders are associated with difficulties in facing life's problems. Thus, mental illness is the amount of the abnormal phenomena showed by a group of individuals in association with specific characteristics by which they differ from the others. However, people use the term mental illness and evaluate it by different criteria depending on a variety of professional and social sensibilities. For instance, scholars of the biomedical model view mental illness in medical and biological terms, while social workers view it in terms of the social context (Perone, 2014). Such understanding and practices influence the form and function of the psychological process that comprises the individual as a subject and social actor. Culture is viewed as the beliefs, practices, and symbols of people within a society, including guidelines for their behavior in given situations (such as religious ceremonies, funerals, weddings, reaching puberty, maturity, and so forth) (Gibson \& Mitchell, 1999, p. 263).

In some African cultures, many accounts of mental illness criticize psychological methods of treatment by saying that mental illness is a myth and that the practices are the products of the western world 
(Horwitz, 2002). The misunderstanding of what constitutes mental illness is influenced by the local concept and other related factors. Therefore, some Africans in Europe suggest that the western world's way of treating mentally ill migrants and refugees has not always been clear. The study by Maercker found that up to $40 \%$ of nonwestern traumatized individuals do not benefit from the western model of therapists (Maercker, 2015). As a result, Ghanaians have exported anti-witchcraft healing shrines to Paris (Parish 2011), and Somali immigrants in Finland complain that western doctors cannot understand or deal with spirits, evil eye, and witchcraft, which are all common causes of mental distress. Somalis seek treatment from Islamic or other specialist healers either in Finland or in Somaliland (Tiilikainen \& Koehn, 2011). Therefore, the understanding of the local concept of mental illness across cultures is essential in trauma treatment because of the important differences that exist between western and nonwestern world.

Furthermore, the study by Nordström Carolyn (1997) has shown that inhabitants of Mozambique were told by counselors to try and keep life as normal as possible during the war, by planting crops, even if they would be ravaged, constructing houses, though they would be destroyed, and using traditional healing rituals to take the war out of people who have witnessed fighting. Moreover, Sverker Finnström's study presented that in the northern part of Uganda, where the Lord's Resistance Army started a civil war in 1986, the Acholi tribe in that area sought nice surroundings in which they made a possible future for themselves, just as they frequently struggled in bad surroundings in which peace and stability were not imaginable, even during lulls in combat. In following their counselors' advice, Acholi people increasingly focused their attention on the spiritual realm and reasserted their ties to history and the wider world, thus, they were able to cope with their traumatic experiences (Finnström, 2008).

In African health beliefs, it is common to attribute mental sickness to the work of ancestors, sorcery, and witchcraft, and supernatural intervention (Marks et al., 2011, p. 73). Thus, Khawaja, White, Schweitzer, \& Greenslade (2008) report that the main trauma coping strategies used by Sudanese refugees in Australia are dependence on religious beliefs, social support and cognitive strategies such as reframing the situation, relying on inner resources and focusing on future aspirations. O'Connor suggests that Christian teaching which includes the texts of scripture, as well as the beliefs and practices from the various traditions, and is beneficial to traumatized individuals (O'Connor, 1998, p. 25). Therefore, western psychologists should be aware of refugees' own cultures, because the culture is the symbols of their meanings and mental baggage that they carry wherever they go. Culture gives individual guidance about how to think, how to feel, and how to act (Furniss, 1994, pp. 18-19). The study by Mölsa, Kuittinen, Tiilikainen, Hankasalo, \& Punamäki (2016) on 128 Somali refugees living in Finland who were traumatized, found that their cultural-religious commitment had helped them to make sense of what happened in the war, and provided them ways of healing their psychological wounds. Thus, therapy would be very beneficial and helpful when a psychologist understands the lifestyle and values of traumatized Africans, and they should be able to interpret their social and cultural practices. As a consequence, among the traumatized Rwandans in Belgium and Finland, some individuals have turned to traditional and religious healers to seek help.

\section{Spiritual Interventions during the Colonial Period, before and after the 1994 Rwandan Genocide against the Tutsis}

\subsection{The Situation of Mental Illness during the Colonial Period and before the 1994 Rwandan Genocide}

The conception of spiritual intervention shows the ways people collaborate with invisible individuals in their daily life. This kind of cultural belief shapes people in such a way that they grow into the concept of humanness. The process of an African cultural spiritualist is established within the community. These spiritual individuals are God, Satan, ancestors, divinities, angels, and demons that constitute forces constantly influence the person's life and protect him/her against diseases, suffering, and harmful events. Besides, those special supernatural individuals enable some Africans to believe and trust that they can do many extraordinary and miraculous works (Bojuwoye, 2005; Kpanake \& Ndoye, 2013).

Historically, traditional spiritual beliefs have been important for Africans, including Rwandans. In Rwandan philosophy, life is thought to be created, recreated, preserved and affirmed by the supreme 
God; they believed that all bad luck and sickness were caused by human wrong-doing, which was caused by an upset in the cosmological realms (Berg, 2003). Until the eve of colonialism, Rwandans believed in Imana (God), a supreme being; they also called him Rurema (the Maker), or Nyagasani (the one who has luck). Apart from God, the Maker, the Rwandans believed in ancestors who were their intermediaries between them and God. Their work was very highly respected, because they were considered the guardians of family affairs, activities, and enforces of the social order (Paris, 1995, Blier, 1996). The ancestors are the 'living dead people' who are members of the family and clan who have died but continue to live on in the community as their guides and mentors. There was also a strong belief that spirits of the dead (like Ryangombe and Nyabingi) mediated between Rwandans and the Imana. At the same time, they feared that the spirits of the dead could come back to haunt the living. They could also consult the spirits of the dead to solve their problems (Banyanga \& Björkqvist, 2017).

In cases of mental illness, brain disorder or madness, some Rwandans believed that they may be caused by malevolent forces, the disobedience of a dead person in the family, witches, poisons, sorcerers, or demons. When these forces were considered malicious, they could consult traditional healers, witchcrafts. Besides, they could also offer sacrifices such as food, beer, goat, chickens, lamb, and a cow so that they may stay in good connections with their gods and ancestors. These rituals are the common ways of communication used to deliver a message to ancestors. Ancestors were consulted in many life situations, including marriage, pregnancies, travels, burial, before and after farming activities as well as in situations of disease.

In some African countries including Rwanda, death was believed to be contagious, and the dead person played a role in the living person's life. In the case of the husband's death, a window's impurity is removed when she has sexual relations with the chosen heir, who is often a brother of her husband (Rwebangira, 1996, p. 27). The act of purification with a chosen heir was to keep the deceased husband in mind and honoring him for the blessing and protection over the family (Jackson \& Karp, 1990, pp. 99-101). In return, bad dreams, mental illness, social misfortunes, nightmares, healing of sickness are some of the common channels that ancestors used when communicating that they were unhappy or content (Kpanake, 2018). Mental illness was often associated with fear and stigma in the family. It was also regarded as a curse on the family rather than illness. A man could be afraid of marrying a girl from that particular family, and women would not marry a man who has a brother or sister who was mentally ill. Thus, family members could not give food and drinks to the mentally ill person in order that he would die. Many families that carried a significant proportion of the financial burden could tie the sick person to a tree or lock him up in the house and continue their daily activities. Finally, mental health treatment services in Rwandan hospitals were very limited (World Health Origination, 2005). Before the 1994 Rwandan genocide, the country had only one mental health care center in Ndera.

\subsection{The Situation of Mental Illness in the Post-Rwandan Genocide}

Mental illness is understood in several different ways, both within and between psychological settings, and in culture more broadly (Tyrer \& Steinberg, 2005; Broome, 2007). Mental illness in Rwanda has been impacted by the 1994 Rwandan genocide, in which more than one million Rwandans were butchered in one of the most intense genocides of the twenty-first century (Anderson \& Menon, 2009, p. 54; Dallaire, 2003, p. 375; United Nations, 2001, p. 7), 250000 - 500000 Rwandan women were raped (Amnesty International, 2004; Des Forges 1999, p. 215; Haffajee, 2006, p. 201), and millions of Rwandans were displaced to Zaïre, now Democratic Republic of Congo (DRC) (Anderson \& Menon, 2009, p. 54; Destexhe, 1995, p. 33; the Republic of Rwanda, 2012). Survivors were exposed to a worse degree of physical and psychological violence ((United Nations, 2001, p.9; Anderson \& Menon, 2009, pp. 54-55). Studies have reported that $96 \%$ of Rwandans during the genocide had witnessed violence in at least one genocide event, $80 \%$ had experienced death in the family, $69 \%$ had witnessed death or injury, $31 \%$ had witnessed rape or sexual assault, and 91\% had thought they would die (United Nations, 2001, p.9; Anderson \& Menon, 2009, pp. 54-55). As a result of these experiences, traumatic stress symptoms due to genocide have caused a high percentage of the Rwandan population to be traumatized. The study indicates that approximately $25 \%$ of the Rwandan population is estimated to display symptoms of posttraumatic stress disorder (PTSD) (Pham, Weinstein \& Longman, 2004), and that many of Rwandan people of different ages still suffer from trauma or mental disorder linked to the 1994 traumatic experience (Munyandamutsa, Nkubamugisha, Gex-Fabry, \& Eytan, 2012). 
Trauma is an uncontrolled reaction to the traumatic experience that people have gone through. In Kinyarwanda, the language spoken in Rwanda, the trauma from the genocide is called ihahamuka which refers to a variety of mental and psychological manifestations originating from the 1994 violence against the Tutsis and its aftermath. It is the result of exposure to an overwhelmingly stressful event or a series of events, such as war, genocide, rape or abuse, and it is a normal response by normal people to an unpleasant situation (Langberg, 1999, pp. 52-53; Schilraldi, 2000, p. 3). Ihahamuka is characterized by terror and hyperarousal which resemble both posttraumatic stress disorder and panic attacks.

Most international organizations base their trauma counseling on the Western model, but because they were unfamiliar with, or even ignored, Rwandan cultural beliefs, many traumatized Rwandans have turned to traditional and religious healers to seek help. Therefore, the trauma healing and coping practices and facilities in Finland and Belgium have been explored and compared. Unlike traumatized Rwandans in Rwanda, Rwandans in Belgium and Finland do not have regular access to traditional and religious healers; but there are persons and organizations in the community, for example, pastors and churches, that provide spiritual and emotional support and consultation. According to Friedman, Keane, and Resick (2007), cultural competency skills are essential to either effectively treat or research any medical condition, and especially psychiatric disorders, because of the interplay between culture and concepts of health or illness, expressions of distress, and healing beliefs and practices. They argue that across all mental illnesses, culture determines the local expression of symptoms (idioms of distress and illness behavior), illness attributions, coping, locally sanctioned treatments, as well as the acceptance of treatments; both western and non-western (Friedman et al. 2007, p. 425). Although, mental health care and physical care has improved dramatically in Kigali (the capital of Rwanda) after the genocide, in rural areas, people still do not have access to mental health care. Mental illness patients need to travel to Kigali for treatment, which is expensive and needs multiple trips to the city (Rugema, Krantz, Mogren, Ntaganira, \& Persson, 2015). All in all, trauma treatment may not be entirely successful and meaningful if a psychologist neglects the clients' life stories and their historical and social backgrounds in therapy.

\section{Methodologies}

\subsection{Sample}

A total of 341 respondents (166 males, 175 females), 50 from Finland and 291 from Belgium, participated in the study. The questions used to obtain different kinds of information from respondents were assembled in a structured questionnaire (Huysamen, 1994, p. 128). The respondents came from different parts of Africa: Burundi, Democratic Republic of Congo, Cameroon, Malawi, Tanzania, Uganda, and Zambia; some came directly from Rwanda. Narrative interviews were conducted in Finland and Belgium in the local language Kinyarwanda. The main reason for collecting the data in Finland and Belgium is that Rwandan people who reside in Finland are a relatively small community; Belgium has a historical tie with the Rwandan people, it has a huge Rwandan community, and it has many Rwandan churchgoers who could be easily contacted for interview. The respondents had come to Belgium either as refugees or on other grounds after the 1994 genocide. At the time of the interview, they were staying in different locations in Belgium: Brussels, Aalst, Liege, Leuven, Charleroi, Limburg, Luxembourg, Namur, Turnhout, Soignies, Sint Niklaas, Tielt, and Vervières. The participants were selected according to the following criteria: the respondents should be above 22 years of age; they should be native Rwandans or born as a consequence of rape during the 1994 genocide and its aftermath, they should speak the local language, Kinyarwanda, and have a residence permit. The interviews were semi-structured with openended questions. The qualitative data was analyzed using inductive or "open" coding (Bernard, 2006, p. 493), while a multivariate analysis of variance (MANOVA) was conducted to measure differences of cultural and other trauma coping mechanisms between Rwandans living in Belgium and Finland.

\subsection{Instrument and Procedure}

A combination of quantitative and qualitative methodologies was applied to approach the research interests of this study. The quantitative data was collected using a paper-and-pencil questionnaire. It 
included several parts related to experiences and coping with traumatization due to the 1994 genocide and its aftermath. In the present study, the areas covered were items regarding cultural methods of coping with the trauma, their experiences of psychological treatment received in their new country, and the healing mechanisms they use to cope with their trauma. The exact wordings of reported items are presented in Table 1 and Table 2. The response range to all items ranged from 0 (does not agree at all) to 4 (completely agree). The data was collected during a 13 month period from 1.8.2015 to 30.8.2016.

\subsection{Ethical Considerations}

Ethical questions were considered very carefully. The study adheres to the principles concerning human research ethics of the Declaration of Helsinki (World Medical Association, 2013), as well as to the guidelines for responsible conduct of research issued by the Finnish Advisory Board on Research Integrity (2012). The respondents were informed of the purpose and procedure of the study. They were aware that their participation was voluntary and that no consequences would follow if they refused to participate. Furthermore, all participants were told that if they felt uncomfortable at any point during the assessment, they could stop without any explanation (Huysamen, 1994, p. 181; Mouton \& Marais, 1996, p. 78). Each interview took between one and a half to two hours.

\section{The Results}

\subsection{Quantitative Results}

A multivariate analysis of variance (MANOVA) was conducted measuring differences of cultural and other trauma coping mechanisms between Rwandans living in Belgium and Finland. The results are presented in Tables 1 and 2 .

Table 1. Descriptive of results of a MANOVA comparing respondents who received therapy and social support, and trauma healing mechanisms, with age as a covariate and 13 dependent variables $(\mathrm{N}=341)$, cf. Table. 2.

\begin{tabular}{l|lll|lll|l|l}
\hline Therapy É social support received & \multicolumn{3}{|c|}{ Belgium } & \multicolumn{3}{|c|}{ Finland } & Total \\
\hline Descriptive statistics & Men & Women & Total & Men & Women & Total & \\
\hline Did authorities provide enough psychologists to & .601 & .779 & .693 & .800 & 1.160 & .980 & .736 \\
deal with trauma? & & & & & & & \\
The benefit from the help of therapists & .623 & .617 & .620 & .760 & .920 & .840 & .653 \\
Support from friends regarding your trauma & 2.210 & 2.201 & 2.206 & 1.520 & 1.920 & 1.720 & 2.134 \\
Support from family regarding your trauma. & 1.928 & 1.819 & 1.871 & 1.720 & 1.760 & 1.740 & 1.852 \\
Support from pastor/priest regarding your trauma & 1.862 & 1.785 & 1.822 & 1 & 1.6 & 1.3 & 1.745 \\
Did you receive support from spiritual healers? & .181 & .281 & .233 & .200 & .240 & .220 & .232 \\
Did you receive support from political leaders? & .399 & .201 & .296 & .320 & .320 & .320 & .299 \\
The use of any traditional means & .797 & 1.081 & .944 & 1.240 & .800 & 1.020 & .956 \\
The use of prayer and belief & 2.377 & 2.651 & 2.519 & 2.480 & 2.800 & 2.640 & 2.537 \\
The use of medicines & .333 & .322 & .328 & .640 & 1.200 & .920 & .415 \\
The joined of other trauma survivors & .797 & 1.154 & .983 & .380 & .448 & .415 & .843 \\
The benefit from trauma survivors & .754 & 1 & .882 & .160 & .040 & .100 & .766 \\
The use of alcohol & .804 & .671 & .735 & 1.320 & 1.240 & 1.280 & .816 \\
\hline
\end{tabular}

As shown in Tables 1 and 2, there were significant differences between respondents from Belgium and Finland. Those living in Belgium scored higher on "received social support in host country", "therapy is given in host country perceived as valuable", "received support from friends to cope with trauma", "received support from pastor/priest to cope with trauma", "joined trauma survivors' group to cope with trauma", and "benefitted from trauma survivors' group attendance". Those living in Finland, on the other hand, scored higher on "used of medicines", traditional means (wedding and dance), and "used of alcohol to cope with trauma". 
Table 2. Correlations between Age and the Thirteen Dependent Variables of the Study $(\mathrm{N}=341)$

\begin{tabular}{ll}
\hline Variables & Age \\
\hline Received social support in the host country & $.18^{* * *}$ \\
Therapy given in the host country perceived as valuable & $.12^{*}$ \\
The personal benefit of therapy received in the host country & .00 \\
Received support from friends to cope with trauma & $.10 \dagger$ \\
Received support from family to cope with trauma & .06 \\
Received support from pastor/priest to cope with trauma & $.23^{* * *}$ \\
Received support from spiritual healers to cope with trauma & -.06 \\
Used traditional means to cope with trauma & -.04 \\
Used Christian prayer to cope with trauma & $.16^{* *}$ \\
Used medicine to cope with trauma & $.18^{* * *}$ \\
Joined trauma survivors' group to cope with trauma & $.27^{* * *}$ \\
Benefitted from trauma survivors' group attendance & $.24^{* * *}$ \\
Used alcohol to cope with trauma & $-.17^{* * *}$ \\
\hline Note. ${ }^{* * *} p \leq .001 ; * * p \leq .01 ; * p \leq .05 ; \dagger \mathrm{p} \leq .10$ &
\end{tabular}

\subsection{Qualitative Results}

Mental illness/trauma may cause persistent fatigue, sleeping disorders, nightmares, fear, anxiety, and flashbacks. Practically, few Rwandans were able to receive counseling from Finnish and Belgian psychologists, and also, few were able to receive governmental social benefits. However, there are still a substantial number of Rwandans who have not benefited from the counseling they received. In their verbal stories, they claim that Belgian and Finnish psychologists do not understand the genocide, their personal experiences, and the cultural context of their mental illness. Consequently, among the Rwandans in Finland and Belgium, many individuals rely on their cultural identities such as churchgoing, Bible reading, and testimonies to cope with their traumatic experiences. A quite small number of Rwandans rely on spiritual healers and their traditional means.

Emotional reactions to trauma may be influenced by an individual's sociocultural history. Most Rwandans in Belgium and Finland have suffered in some way from the 1994 genocide and lost one or more family members: siblings, parents, wives, husbands, children, as well as neighbors, friends, and property. Some have family members still scattered throughout the refugee camps in African countries, while others have family members in prison. Some respondents had been imprisoned for many years in Rwanda without any formal charge, and they did not receive any compensation. As the outcome of these experiences, the percentage of Rwandans who still suffer from posttraumatic stress disorder (PTSD) symptoms is seriously high. Trauma may influence an individual's sociocultural factors and emotions. Therefore, young Rwandans feel that they do not know much about their country and that they have lost their cultural identity. Finally, the study shows that cultural beliefs and religion have played an important role in coping with trauma and reconciliation among Rwandan churchgoers in Finland and Belgium.

\section{Discussion}

Many mental illness cases in Rwanda have been triggered by the 1994 Rwandan genocide and its aftermath. Unlike traumatized Rwandans in Rwanda, Rwandans in Belgium and Finland do not necessarily have regular access to traditional and religious healers; however, there are persons in the community, for example, pastors and churches that provide spiritual and emotional support and consultation.

This study shows that there are many Rwandan individuals with significant post-trauma mental health problems, who are likely to continue suffering from trauma-related conditions for years. Some of the traumatized Rwandans in Finland and Belgium may have specific conditions that require medical attention in terms of psychological interventions. However, some Rwandans use self-damage ways (smoking cigarettes, drinking too much alcohol) to cope with emotional or physical distress and others 
rely on medicines to get help for their mental pain. Therefore, trauma treatment may not be entirely successful and meaningful if a psychologist neglects the clients' life stories and their historical and social backgrounds in therapy.

It appears that Rwandans in Finland suffered more from their trauma, due to loneliness and the language barrier. Mostly, Finnish and Belgian treatment of mental illness is based on a Western model of trauma. There is a little attention paid to make the interventions culturally sensitive. Studies have shown that traditional and religious healing, religious communities and storytelling events have been reported as an effective means of dealing with traumatic memories (Schiraldi 2000, Neimeyer 2001). Therefore, for counselors and psychiatrists, the understanding of a person's cultural concepts of mental illness is a useful way of treating the illness.

\section{References}

1. Anderson, P., Menon, J. (2009). Violence performed: Local roots and global routes of conflict. New York: Palgrave and Macmillan.

2. Banyanga, J. A., \& Björkqvist, K. (2017). The dual role of religion regarding the Rwandan 1994 genocide: Both instigator and healer. Pyrex Journal of African Studies and Development, 3, pp. 1-12.

3. Bernard, R. H. (2006). Research Methods in Anthropology: Qualitative and Quantitative Approaches. Lanham, Maryland: AltaMira Press.

4. Blier, S. P. (1996). African vodun: Art, psychology, and power. Chicago, IL: University of Chicago Press.

5. Bojuwoye, O. (2005). Traditional healing practices in Southern Africa: Ancestral spirits, ritual ceremonies, and holistic healing. In R. Moodley, \&. W. West /Eds.). Integrating traditional healing practices into counseling and psychotherapy (pp. 61-72). Thousand Oaks, CA: SAGE.

6. Broome, M. R. (2007). Taxonomy and ontology in psychiatry: A survey of recent literature. Philosophy, and Psychology, 13, pp. 303-319.

7. Dallaire, R. (2003). Shake hands with the devil: The failure of humanity in Rwanda. New York: Carroll \& Graf.

8. Des Forges, A. L. (1999). Leave none to tell the story: Genocide in Rwanda. New York, NY: Human Rights Watch.

9. Destexthe, A. (1995). Rwanda and genocide in the twentieth century. New York: New York University Press.

10. Finnish Advisory Board on Research Integrity. (2012). Guidelines for responsible conduct of research and procedures for handling allegations of misconduct in Finland. http://www.tenk.fi/sites/tenk.fi/files/ HTK_ohje_2012.pdf

11. Finnström, S. (2008). Living with bad surroundings: War, history, and everyday moments in northern Uganda. Durham: Duke University Press.

12. Friedman, M. J., Keane, M. T. \& Resick, A. P. (2007). Handbook of PTSD: Science and practice. New York, NY: Guilford Press.

13. Furniss, G. M. (1994). The social context of pastoral care: Defining the life situation. Louisville, KY: Westminster John Knox Press.

14. Gibson, R. L., \& Mitchell, M. H. (1999). Introduction to counselling and guidance. Upper Saddle River, NJ: Merrill.

15. Haffajee, R. L. (2006). Prosecuting crimes of rape and sexual violence at the ICTR: The application of joint criminal enterprise theory. Harvard Journal of Law and Gender, 29, pp. 201-221.

16. Hitlin, S. (2011). Values, personal identity, and moral self. In S. J. Schwartz, K. Luyckx, \& V. L. Vignoles (Eds.), Handbook of Identity theory and research (pp. 515-429). New York, NY: Springer.

17. Huysamen, G. K. (1994). Methodology for the social and behavioral science. Cape Town, South Africa: Oxford University Press.

18. Jackson, M., \& Karp, I. (1990). Personhood and Agency: The experience of self and other in African cultures. Uppsala, Sweden: Uppsala University Press.

19. Khawaja, N. G., White, K. M., Schweitzer, R., \& Greenslade, J. (2008). Difficulties and coping strategies of Sudanese refugees: A qualitative approach. Transcultural Psychiatry, 45, pp. 489-512.

20. Kpanake, L. (2018). Cultural concepts of the person and mental health in Africa. Transcultural Psychiatry, 55, pp. 198-218. 
21. Kpanake, L., \& Ndoye, O. (2013). Counseling and psychotherapy in francophone West- Africa: Creating a future vision. In R. Moodley, U. P. Gielen, \& R. Wu (Eds.). Handbook of counseling and psychotherapy in an international context (pp. 30-39). New York, NY: Routledge.

22. Langberg, D. M. (1999). On the threshold of hope: Opening the door to hope and healing for sexual abuse. Wheaton, IL.: Tyndale.

23. Maercker, A. (2015). You are not alone! The power and pitfalls of social contexts in PTSD. Keynote lecture at XIV Conference of European Society for Traumatic Stress Studies, 11 June, Vilnius, Lithuania.

24. Maercker, A., Schutzwohl, M., \& Zahava, S. (1999). Post-traumatic stress disorder: A lifespan developmental perspective. Seattle \&Toronto: Hogrefe \& Huber.

25. Marks, D. F., Murray, M., Evans, B., \& Estacio, E.V. (2011). Health psychology: Theory, research and practice. Los Angeles, CA: Sage.

26. Mölsä, M., Kuittinen, S., Tiilikainen, M., Honkasalo, M. L., \& Punamäki, R. L.(2016). Mental health among older refugees: the role of trauma, discrimination, and religiousness. Aging \& Mental Health, 21, pp. 829-837.

27. Mouton, J. \& Marais, H. C. (1996). Basic Concepts in the methodology of the social sciences. Pretoria, South Africa: Human Sciences Research Council.

28. Munyandamutsa. N., Nkubamugisha, M. P, Gex-Fabry, M., Eytan, A. (2012). Mental and physical health in Rwanda 14 years after the genocide. Soc Psychiatry Psychiatr Epidemiol, 47, pp. 1753-1761.

29. Neimeyer, R. A. (2001). Meaning reconstruction and the experience of loss. Washington, DC: American Psychological Association.

30. Nordström, C. (1997). A different kind of story to tell. Philadelphia, PA: University of Pennsylvania.

31. O'Connor, T. J. (1998). Clinical pastoral supervision and the theology of Charles Gerkin. Waterloo, Ontario, Canada: Wilfrid Laurier University Press.

32. Paris, P. J. (1995). The spirituality of African people. Minneapolis, MN: Augsburg Fortress.

33. Perone, K. A. (2014). The Social construction of mental illness for lesbian. Gay, bisexual, and transgender persons in the United States. Qualitative Social Work, 13, pp. 766-771.

34. Pham, P. N., Weinstein, H. M., \& Longman, T. (2004). Trauma and PTSD symptoms in Rwanda: Implications for attitudes toward justice and reconciliation. JAMA, 292, pp. 602-612.

35. Pronin, E. (2008). How we see ourselves and how we see others. Science, 320, pp. 1177-1180.

36. Rob, W., \& Rosalyn, D. C. (2014). Stigma, agency, and recovery amongst people with severe mental illness. Social Science \& Medicine, 107, pp. 1-8.

37. Rugema, L., Krantz, G., Mogren I., Ntaganira, J., \& Persson, M. (2015). A constant struggle to receive mental health care: health care professionals acquired experience of barriers to mental health care services in Rwanda. BMC Psychiatry, 15 (1): 314.

38. Rwebangira, M. K. (1996). The Legal Status of Women and Poverty in Tanzania. Uppsala, Sweden: Nordic African Institute.

39. Tyrer, P. \& Steinberg, D. (2005). Models for mental disorder: Conceptual models in psychiatry. Chichester: Wiley.

40. United Nations. (2001). Report of the third United Nations conference on the least developed countries. Brussels, Belgium: United Nations General Assembly.

41. World Health Organization. (2005). Mental health substance abuse: Mental health Atlas. WHO, Geneva.

42. World Medical Association Declaration of Helsinki. (2013). Ethical principles for medical research involving human subjects. JAMA, 310, pp. 2191-2194. 